\title{
Schnellbestimmung der Cholinesterase
}

\author{
Von A. Härted, W. Gross und H. LANG \\ Aus der Biochemischen Abteilung (Leiter: Dr. H. Lang) der Fa. E. Merck AG, Darmstadt
}

(Eingegangen am 19. März 1966)

\begin{abstract}
Es wird ein verbesserter Schnelltest zur Cholinesterase-Bestimmung im Serum beschrieben. Das Verfahren ist gekennzeichnet durch die Verwendung eines Reagenzpapiers und eines geeichten kontinuierlichen Farbbandes, mit dessen Hilfe die Cholinesterase-Konzentration nach einer Inkubationszeit von 6 Minuten aus der Farbänderung des Reagenzpapiers abgelesen werden kann.
\end{abstract}

An improved rapid test is described for the determination of cholinesterase in serum. The method is characterised by the use of a reagent paper and a graduated continuous colour band, from which the cholinesterase concentration can be read as a colour change after 6 minutes incubation.

Die im Plasma nachweisbare Cholinesterase wird in den Leberzellen gebildet $(1,2)$ und in die Blutbahn abgegeben. Normalerweise ist die Konzentration dieses Enzyms im Plasma recht hoch. Geringere Konzentrationen weisen auf Lebererkrankungen (3-9) bzw. auf Vergiftungen mit Phosphorsäureestern (z. B. E 605) hin $(1,10)$ und besitzen deshalb diagnostische Bedeutung. Außerdem weisen mehrere Autoren $(1,4,10,11)$ auf die Wichtigkeit der präoperativen Cholinesterase-Bestimmung hin, da bei Patienten mit geringen Serum-Cholinesterase-Konzentrationen nach Gabe von Muskelrelaxantien Anästhesie-Zwischenfälle auftreten können. Experimentell wird die Cholinesterase-Konzentration durch Messung der Hydrolysegeschwindigkeit von Cholinestern bestimmt, z. B.

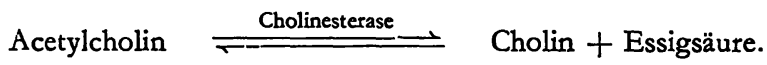

Für die praktische Durchführung der Analyse gibt es viele Vorschriften, die sich durch die Art des verwendeten Esters, des Puffers, durch die Inkubationszeit und -temperatur, die Indikatorreaktion und die Meßtechnik unterscheiden. $\mathrm{Da}$ es hierüber ausführliche Übersichtsarbeiten gibt $(12,13)$, erübrigt sich eine genauere $\mathrm{Be}-$ sprechung.

Besonders erwähnt sei jedoch das Cholinesterase-Testpapier von Herzfeld und Stumpr (14), das meist in einer Modifikation nach SAILER und BRAUnSTEINER (15) angewendet wird. Es handelt sich um ein pH-Indikatorpapier, das mit Acetylcholin imprägniert ist (6). Beim Befeuchten mit Serum wird das Acetylcholin durch die Cholinesterase gespalten. Die freiwerdende Essigsäure bewirkt eine Farbänderung des Indikators. Die Zeit, in der ein bestimmter Farbton erreicht wird, dient als $\mathrm{MaB}$ für die Cholinesterase-Konzentration. $\mathrm{Da}$ dieses Testpapier mit einfachen Mitteln eine halbquantitative Bestimmung ermöglicht, ist es besonders für kleinere Laboratorien und für die Arztpraxis geeignet.

Die Anwendung dieses Testverfahrens im klinischen Laboratorium wird jedoch durch folgende Umstände erschwert:

1. Das Papier muß während der gesamten Inkubationszeit beobachtet werden. 2. Die Messung von diagnostisch interessanten Proben, nämlich von geringen Cholinesterase-Konzentrationen, kann bis zu 2 Stunden dauern
3. Im Vergleich zu den üblichen Cholinesterase-Einheiten erhält man reziproke Werte. 4. Das Verfahren berücksichtigt nicht den $\mathrm{pH}$-Wert des Serums zu Beginn der Inkubation. Da Seren beim Aufbewahren unterschiedliche Mengen Ammoniak abspalten, die beim Test einen zusätzlichen Verbrauch an Säure und damit eine Verlängerung der Inkubationszeit verursachen, werden die Ergebnisse ungenau.

Deshalb ist es eine wesentliche Erleichterung, wenn eine gedruckte $p H$-Skala anstatt einer einzigen Vergleichsfarbe benutzt wird. Als $\mathrm{MaB}$ für die CholinesteraseKonzentration verwendet man hierbei den nach einer festen Inkubationszeit erreichten $\mathrm{pH}$-Wert und nicht die zum Erreichen eines bestimmten $\mathrm{pH}$-Wertes benötigte Zeit. Fehler, die durch unterschiedliche pH-Werte der Seren verursacht werden, können durch eine $\mathrm{pH}-\mathrm{Ab}$ lesung zu Beginn der Inkubation ausgeschaltet werden. Durch diese Methode werden die langen Beobachtungszeiten auf zwei Ablesungen zu vorher feststehenden Zeitpunkten reduziert.

$\mathrm{Da}$ der $\mathrm{pH}$-Bereich, der sich mit Hilfe eines einzigen Indikators differenzieren läßt, zu klein ist, werden zivei Indikatoren mit verschiedenen Umschlagspunkten verwendet. Besonders bewährt hat sich ein Gemisch aus Phenolrot und Naphtholphthalein, dessen Farbe sich bei der Cholinesterase-Bestimmung von violett über rot und orange nach gelb ändert.

Zur Erzielung einer kurzen Inkubationszeit darf das Reagenzpapier nicht zu stark gepuffert sein, da sonst die während der Inkubation freiwerdende Esșigsäure den $\mathrm{pH}-$ Wert zu wenig verändert. Die Pufferkapazität der Probe bestimmt deshalb die pH-Änderung pro $\mu \mathrm{Mol}$ freigesetzter Säure. Trotzdem ist eine für Humanseren gültige Umrechnung von $\mathrm{pH}$-Differenzen in Internationale Enzymeinheiten möglich, da die Pufferkapazitäten der einzelnen Seren im pH-Bereich von 6,0 bis 8,5 hinreichend gut übereinstimmen (s. Tab. 1). Die Umrechnung von pH-Differenzen in CholinesteraseEinheiten kann man sich ersparen, wenn man die pHSkala in Enzymeinheiten umeicht. Sofort nach der Inkubation kann dann die Cholinesterase-Konzentration in Internationalen Enzymeinheiten pro $\mathrm{ml}$ durch eine einfache Differenzbildung ermittelt werden. 
Tab. 1 pH-Wertc und Pufferung bei der Cholinesterase-Schnellbestimmung (Umrechnung von pH-Differenzen in $\mu$ Mol Säure)

\begin{tabular}{|c|c|c|c|c|c|c|c|}
\hline \multirow[t]{2}{*}{ Probe. } & \multirow{2}{*}{$\begin{array}{c}\text { Zeit } \\
\text { nach } \\
\text { der } \\
\text { Entnahme } \\
\text { in Stdn. }\end{array}$} & \multirow{2}{*}{$\begin{array}{l}\text { Lage- } \\
\text { rungs- } \\
\text { tempe- } \\
\text { ratur } \\
\left({ }^{\circ} \mathrm{C}\right)\end{array}$} & \multirow[t]{2}{*}{$\mathrm{pH}( \pm 1 \sigma)$} & \multicolumn{4}{|c|}{$\begin{array}{c}\mu \text { Mol Säure }( \pm 1 \sigma) \text {, die bei } 1 \mathrm{~m} l \text { Probe (bzw. } 25 \mathrm{~cm}^{2} \text { Reagenz- } \\
\text { papier) den } \mathrm{pH} \text {-Wert von } \mathrm{pH}=8,0 \text { auf folgende Werte } \\
\text { verändert }\end{array}$} \\
\hline & & & & $\mathrm{pH}=7,5$ & $\mathrm{pH}=7,0$ & $\mathrm{pH}=6,5$ & $\mathrm{pH}=6,0$ \\
\hline Humanserum $x$ & 0,6 & 25 & $7,75 \pm 0,03$ & & & & \\
\hline Humanserum $x$ & $2-3$ & 25 & $8,06 \pm 0,06$ & $4,7 \pm 0,4$ & $9,3 \pm 1,0$ & $16,9 \pm 1,5$ & $27,6 \pm 2,2$ \\
\hline Humanserum $\mathrm{x}$ & 7 & 25 & $8,2 \pm 0,1$ & & & & \\
\hline Humanserum $x$ & 28 & 4 & $8,2 \pm 0,05$ & $4,9 \pm 0,5$ & $9,6 \pm 0,5$ & $16,0 \pm 0,7$ & $26,2 \pm 1,6$ \\
\hline Humanserum $x$ & 28 & 25 & $8,4 \pm 0,3$ & $4,4 \pm 0,8$ & $8,5 \pm 1,0$ & $14,5 \pm 1,6$ & $22,1 \pm 2,7$ \\
\hline Humanserum $\mathrm{xx}$ & $3-100$ & 4 & $7,9=8,9$ & $3,9 \pm 0,3$ & $8,7 \pm 0,8$ & $15,1 \pm 1,1$ & $23,9 \pm 2,2$ \\
\hline $0,025 \mathrm{M}$ & & & & & & & \\
\hline Phosphatpuffer & &.. & & 3,4 & 8,7 & 15,5 & 22,2 \\
\hline Reagenzpapier & & & & 0,23 & 0,32 & 0,38 & 0,52 \\
\hline
\end{tabular}

x 6 Blutspenderseren $x \times 20$ Seren aus einem Kliniklabor

Die Tatsache, daß beim Freiwerden einer bestimmten Säuremenge die $\mathrm{pH}$-Änderung nur von der Pufferkapazität der Probe abhängt, bringt einen wichtigen Vorteil mit sich: das Ergebnis ist praktisch unabhängig vom Probevolumen, da nur das Verhältnis von Cholinesterase-Menge zur Puffermenge in die Messung eingeht. Substrat- und Indikatorkonzentrationen werden nämlich durch das begrenzte Saugvermögen des Testpapiers genügend konstant gehalten. Aus diesen Gründen erübrigt sich ein genaues Dosieren der Probe in Grenzen von 0,03 bis $0,15 \mathrm{ml}$ Serum pro $\mathrm{cm}^{2}$ Testpapier. Bei großem Serumüberschuß besteht allerdings die Gefahr, da $ß$ bei Paralleluntersuchungen auf einer Glasplatte die Proben ineinanderlaufen. Deshalb verwendet man als Unterlage am besten eine Testplatte, bei der die Auflageflächen für die Reagenzpapiere von Rinnen umgeben sind, die den Serumüberschuß aufnehmen. Hiermit können im Routinebetrieb bequem 4 Bestimmungen nebeneinander durchgeführt werden.

Eine weitere wichtige Verbesserung läßt sich folgendermaßen erreichen: Man verwendet als Vergleichsskala ein Farbband, das in kontinuierlicher Reihenfolge alle Farbnuancen enthält, die im Laufe der Reaktion sichtbar werden. Hierdurch wird die Reproduzierbarkeit der Ablesungen im Vergleich zu den üblichen stufenweisen pH-Skalen etwa um den Faktor 2 verbessert. Auch die absolute Genauigkeit eines Farbbandes ist besser, da die Eichung erst nach dem Farbdruck durch Markierungsstriche erfolgt. Außerdem kann das Farbband so hergestellt werden, daß durch einen nicht linearen $\mathrm{Maßstab}$ die Cholinesterase-Konzentrationen im diagnostisch interessanten Bereich am genauesten abgelesen werden können.

\section{Eicbung eines Farbbandes}

Experimentell wird die Eichung eines gedruckten Farbbandes, das für Humanserẹn bei fester Inkubationszeit die Zahl der Internationalen Einheiten pro $\mathrm{m} l$ angibt, folgendermaßen vorgenommen:

Zunächst ordnet man dem Farbband eine vorläufige mm-Skala zu. Dann führt man den Cholinesterase-Test mit dem Reagenzpapier durch und liest sofort nach dem Befeuchten und dann nach jeder vollen Minute den zugehörigen Farbwert in $\mathrm{mm}$ ab. Die Ergebnisse werden in Abhängigkeit von der Zeit graphisch aufgetragen. Man ermittelt die Steigung dieser Kurve bei jedem 10-mm-IWert, dividicrt diese Zahlen durch die Cholinesterase-Konzentration, die getrennt mit Hilfe einer exakten Vergleichsmethode ermittelt wird und trägt die Ergebnisse in Abhängigkeit von der Farbbandlänge in ein Koordinatensystem ein. $\mathrm{Da}$ die Ablesungen nach je einer Minute Inkubationszeit mit einem relativ großen Fehler behaftet sind, werden die Messungen an etwa 40 Seren wiederholt. Die zugehörige Kurve ist ein Maß für die Geschwindigkeit der Farbänderung (ausgedrückt in $\mathrm{mm}$ Farbband pro Minute) bei Inkubation mit einem Serum, das 1 Einheit Cholinesterase pro $\mathrm{m} l$ enthält. Aus dieser Kurve können die Farbtöne (ausgedrückt in $\mathrm{mm}$ Farbband) für verschiedene Inkubationszeiten und Cholinesterase-Konzentrationen berechnet werden. Hieraus ergibt sich die Lage der Eichstriche für die gewünschte Inkubationszeit. Zur Kontrolle wird anschließend eine Fehleranalyse durchgeführt. Hierzu wird der Cholinesterase-Gehalt von einer größeren Zahl Seren mit Hilfe des näherungsweise geeichten Farbbandes und außerdem mit einer exakten Vergleichsmethode bestimmt. Die Differenzen werden in Abhängigkeit von den abgelesenen Anfangs- und Endwerten graphisch dargestellt. Hierbei können auch kleinere systematische Fehler leicht erkannt und durch cine entsprechende Korrektur der Eichstriche ausgeschaltet werden.

Diese Art der Eichung berücksichtigt die unterschiedlichen Anfangs-pH-Werte und den nichtlinearen Verlauf der Skala. Durch die Vielzahl der Proben werden die Fehler infolge unterschiedlicher Pufferkapazitäten auf ein Minimum reduziert.

\section{Methodik}

\section{Cholinesterase-Schnellbestimmung}

Die Cholinesterase-Schncllbestimmung erfolgt mit Hilfe der Merckotest-Packung "Cholinesterase" entsprechend den Angaben des Beilagezettels. Bei einigen Untersuchungen ierden zusätzlich Ablesungen nach jeder vollen Minute vorgenommen, um durch eine graphische Auswertung einen besseren Úberblick über den Verlauf der Reaktion zu erhalten. Um bei der Bestimmung des Normalbereiches jede Beeinflussung des Untersuchers durch das von den exakten Methoden her bekannte Ergebnis auszuschalten, werden die Farben zunächst mit Hilfe der $\mathrm{mm}$-Skala charakterisiert und erst nach dem Versuch in Cholinesterase-Einheiten umgerechnet.

Cholinesterase-Bestimmung durcl) Titration bei konstantem pH (Vergleichsmethode)

Zur Titration der freiwerdenden Essigsäure bei konstantem pH werden Vorschrift und Geräte der Fa. Radiomete:, Kopenhagen, verwendet, da hierbei am gleichen Substrat gemessen wird. Wenn kein automatischer Titrator zur Verfügung steht, kann die Vorschrift folgendermaßen abgewandelt werden: $1 \mathrm{~m} /$ Serum wird mit $25 \mathrm{ml}$ physiolog. Kochsalzlösg. verdünnt und im Thermostat auf $37^{\circ}$ 


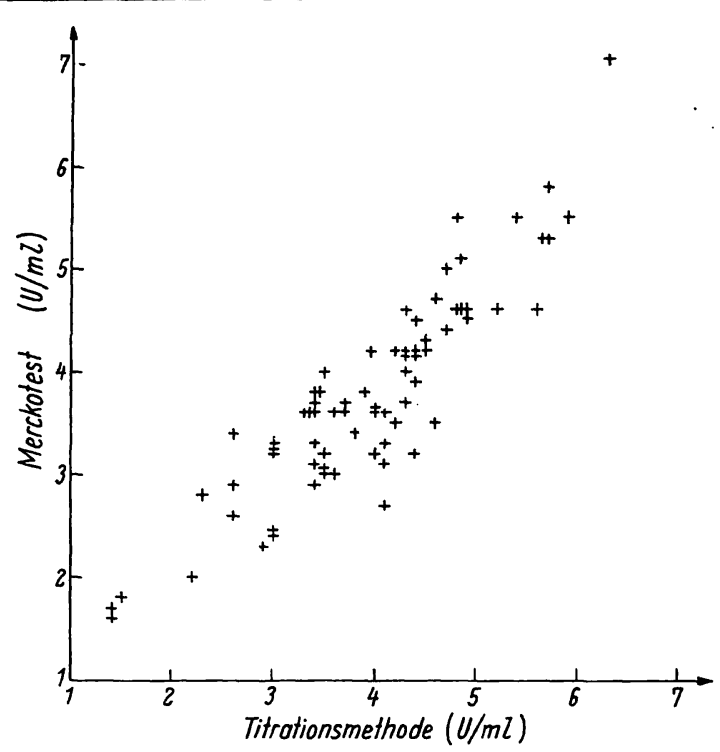

Abb. 1

Vergleich der Cholinesterase-Schnellbestimmung mit der Cholinesterase-Titrationsmethode

Regressionsgerade: $y=0,27+0,90 x$; Streuung: $s_{y x}=0,31$; Korrelationskoeffizient: $r=0,92$

erwärmt. Dann gibt man $2 \mathrm{ml}$ einer 10 -proz. Lösung von Acetylcholinchlorid in Wasser hinzu und stellt durch Zugabe von 0,02N $\mathrm{NaOH}$ das $\mathrm{pH}$ von 7,7 $\pm 0,1$ ein (Magnetrührer, $\mathrm{pH}-$ Meßgerät). Wenn das $\mathrm{pH}$ von 7,5 erreicht ist, setzt man eine Stoppuhr in Gang. Ist das $\mathrm{pH}$ von 7,3 erreicht, fügt man weitere Natronlauge hinzu, bis das $\mathrm{pH}$ von 7,7 $\pm 0,1$ erreicht ist. Wenn anschließend das $\mathrm{pH}$ wieder auf 7,5 gefallen ist, liest man Zeit und Natronlaugeverbrauch ab. Man wiederholt die Messung einige Male und trägt anschließend den Natronlaugeverbrauch in Abhängigkeit von der Zeit in ein Koordinatensystem ein. Bei der Auswertung (Zahl der $\mu \mathrm{Mol}$ verbrauchter Lauge pro Minute) wird eine Blindwertmessung berücksichtigt, bei der an Stelle des Serums $1 \mathrm{ml} 0,1 \mathrm{M}$ Phosphatpuffer verwendet wird.

\section{Messung der Pufferkapazität}

Die Probe $\left(0,4 \mathrm{~m} l\right.$ Serum bzw. $10 \mathrm{~cm}^{2}$ zerkleinertes Reagenzpapier) wird in $3 \mathrm{~m} l$ physiolog. Kochsalzlösg. gelöst bzw. aufgewirbelt. Mit Hilfe einer Dosierpumpe gibt man bei konstanter Strömungsgeschwindigkeit $(0,2 \mathrm{~m} / \mathrm{Min}$.) unter magnetischem Rühren $0,05 \mathrm{~N}$ $\mathrm{HCl}$ aus einer $1 \mathrm{ml}$-Bürette hinzu. Durch ein pH-Gerät mit Glaselektrode und Kompensationsschreiber wird laufend das $\mathrm{pH}$ registriert. Aus der aufgezeichneten Kurve wird die verbrauchte Säure pro $\mathrm{pH}$-Diffcrenz für die verschiedenen $\mathrm{pH}$-Bereiche $\mathrm{zw}$ wschen 6,0 und 8,0 beres:hnet. Blindwerte, die im Parallelversuch ohne Probe erhalten werden, müssen beim Ergebnis berücksichtigt werden.

\section{Ergebnisse}

Die Brauchbarkeit der Methode wird an einer größeren Zahl Humanseren überprüft. Man erhält folgende Ergebnisse:

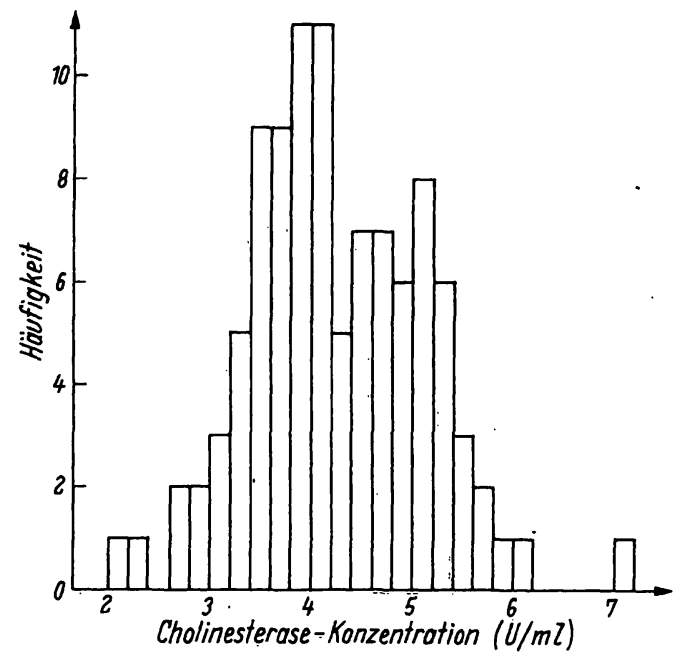

Abb. 2

Häufigkeitsverteilung der Cholinesterase-Werte (Schnellbestimmung) von 101 Blutspenderseren

1. Die Inkubationszeit von 6 Minuten ist optimal.

2. Bei den meisten Seren liegen die nach jeder Minute (in Einheiten) abgelesenen Farbwerte, dargestellt in Abhängigkeit von der Zeit, auf einer Geraden. (Abweichung der einzelnen Ablesung bei Verwendung eines auf 6 Min. geeichten Farbbandes: $1 \sigma= \pm 0,2 \mathrm{U} / \mathrm{m} l$ (Acetylcholin $\left.37^{\circ}, \mathrm{pH}=7,0\right)$ ).

3. Bei extrem hohen bzw. niedrigen CholinesteraseKonzentrationen kann die Inkubationszeit auch bei Verwendung eines auf 6 Min. geeichten Farbbandes um den Faktor $F(0,5 \leqq F \leqq 2)$ geändert werden, wenn das Ergebnis mit $1 / F$ multipliziert wird.

4. Die Ablesungen am Beginn und am Ende der Inkubation sind völlig ausreichend. Durch Ablesungen nach jeder Minute und anschließende graphische Auswertung wird die Korrelation zur Titrationsmethode praktisch nicht verbessert.

5. Das Testpapier liefert im Vergleich zur Titration im Mittel um $\pm 0,5 \mathrm{U} / \mathrm{m} l(1 \sigma)$ abweichende Ergebnisse, wobei die erzielte Genauigkeit etwas vom Untersucher abhängt (bester Wert: $1 \sigma=0,35$; schlechtester Wert: $1 \sigma=0,8 \mathrm{U} / \mathrm{m} l$ ) (s. Abb. 1).

6. Der Normalbereich bei der Cholinesterase-Schnellbestimmung beträgt 3,0-5,7 U/ml (Acetylcholin, $37^{\circ}$, $\mathrm{pH}$ 7,5) (Häufigkeitsverteilung s. Abb. 2).

Wir danken Fräulein R. Frnkenauer und Frau A. Hrmser für die Durchführung der Versuche sowie Herrn Dr. W. Rrck für die Erprobung im klinischen Laboratorium.

\section{Literatur}

1. Richterich, R., Praxis 50, 624 (1961). - 2. Stefenelli, N., Klin. Wschr. 39, 1019 (1961). - 3. Doenicke, A. und S. SchmiDINGER, Med. Klin. 60, 2012 (1965). - 4. LANG, W. und G. INTSEsuloglu, Klin. Wschr. 40, 312 (1962). - 5. MAIER, E. H., Dtsch. med. Wschr. 81, 1674 (1956). - 6. RICHTERICH, R., Schweiz. med. Wschr. 92, 263 (1962). - 7. Stefenelli, N. und F. Wewalka, Acta hepato splend. 8, 379 (1961). - 8. Weidemann, H., Med. Klin. 58, 1795 (1963). - 9. WeidemanN, H. und J. Nocker,
Münch. med. Wschr. 39, 1019 (1961). - 10. RIEDER, H. P., Șchweiz med. Wschr. 95, 969 (1965). - 11. Goedde, K. W., K. AltLand und K. Bross, Dtsch. med. Wschr. 88, 2510 (1963). - 12. Glick, . D., Methods of Biochemical Analysis Vol. 5, 1-63. Interscience Publ., New York (1957). - 13. Stumpr, C., Zschr. Vitamin-, Hormon- Ferm.forsch. 8, 36 (1956). - 14. Herzfeld, E. und C. Stumpr, Wien. klin. Wschr. 67, 874 (1955). - 15. SAILER, S. und H. Braunsterner, Klin. Wschr. 37,986 (1959).

\section{Dr. H. Lang}

Biochem. Abt. der E. Merck AG 61 Darmstadt, Frankfurter Str. 